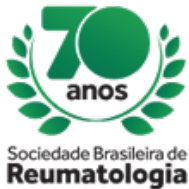

CENTRO DE EVENTOS DO CEARA O4 A 07 DE SETEMBRO

\title{
ACUTE GENERALIZED EXANTHEMATOUS PUSTULOSIS DUE TO HYDROXYCHLOROQUINE: CASE REPORT IN A PATIENT WITH AMYOPATHIC DERMATOMYOSITIS
}

Daniel Neri (Rheumatology Fellow, Clinical Hospital, Pernambuco Federal University, Recife, PE, Brasil), Filipe Lima (Rheumatology Fellow, Clinical Hospital, Pernambuco Federal University, Recife, PE, Brasil), Bruno Fontes (Rheumatology Fellow, Clinical Hospital, Pernambuco Federal University, Recife, PE, Brasil), Jessica de Araujo (Dermatology, Clinical Hospital, Pernambuco Federal University, Recife, PE, Brasil), Henrique Mariz (Rheumatology, Clinical Hospital, Pernambuco Federal University, Recife, PE, Brasil), Claudia Marques (Rheumatology, Clinical Hospital, Pernambuco Federal University, Recife, PE, Brasil), Angela Duarte (Rheumatology, Clinical Hospital, Pernambuco Federal University, Recife, PE, Brasil), Laurindo da Rocha Jr (Rheumatology, Clinical Hospital, Pernambuco Federal University, Recife, PE, Brasil)

\section{BACKGROUND}

Acute generalized exanthematous pustulosis (AGEP) is a rare and severe cutaneous adverse reaction. The majority of the cases reported in the literature are attributed to antibiotics. It is an acute rash characterized by numerous, nonfollicular, sterile pustules, arising on an exanthematous and edematous skin. It is a serious adverse reaction and often accompanied by fever and leukocytosis. Herein is reported a case of AGEP in a patient with amyopathic dermatomyositis caused by hydroxychloroquine.

\section{CASE REPORT}

A 38-year-old woman, diagnosed with amyopathic dermatomyositis 2 years ago, had being treated with prednisone and methotrexate, but despite the high doses used, she did not present a satisfactory response to disease cutaneous involvement. So, Azathioprine was chosen to improve therapy. While awaiting Azathioprine release by the public health system, Hydroxychloroquine was prescribed. After 18 days of Hydroxychloroquine use, the patient began to present desquamative lesions and pustules in the trunk, upper and lower limbs. Due to possibility of pharmacodermia, the drug was discontinued and a skin biopsy was performed. Nevertheless, there was progression of the lesions associated with secondary infection. Given the hypothesis of Acute Generalized Exanthematous Pustulosis (AGEP), the dose of prednisone was increased to $1 \mathrm{mg} / \mathrm{kg} /$ day. Patient progressed with slow and gradual improvement of the lesions, being decided after seven days of treatment perform Methylprednisolone pulse therapy (125 $\mathrm{mg} /$ day) for 03 days to optimize response and to taper corticoid, followed by decrease of the prednisone dose to $0.5 \mathrm{mg} / \mathrm{kg} /$ day. Histopathological analysis of the lesion revealed epidermal acanthosis with presence of occasional pustules, parakeratotic hyperkeratosis with permeable neutrophils (microabscesses) and predominantly lymphocytic inflammatory infiltration around the superficial vascular plexus, an AGEP compatible description. Thereafter, a greater clinical improvement of lesions was seen with an excellent response to the treatment performed.

\section{CONCLUSION}

Acute generalized exanthematous pustulosis is an uncommon side efect of hydroxychloroquine treatment and there are few cases published. Rheumatologists should consider this condition in patients with underlying rheumatologic diseases and new-onset pustulosis under hydroxychloroquine therapy. 